\title{
Stabilization of Sur8 via PKC $\alpha / \delta$ degradation promotes transformation and migration of colorectal cancer cells
}

\author{
Kug Hwa Lee ${ }^{1,2}$, Woo-Jeong Jeong ${ }^{1,2}$, Pu-Hyeon Cha ${ }^{1,2}$, Sang-Kyu Lee ${ }^{1,2}$, Do Sik \\ Min $^{1,3}$ and Kang-Yell Choi ${ }^{1,2}$ \\ ${ }^{1}$ Translational Research Center for Protein Function Control, Yonsei University, Seoul, South Korea \\ ${ }^{2}$ Department of Biotechnology, College of Life Science and Biotechnology, Yonsei University, Seoul, South Korea \\ ${ }^{3}$ Department of Molecular Biology, College of Natural Science, Pusan National University, Pusan, South Korea \\ Correspondence to: Kang-Yell Choi, email: kychoi@yonsei.ac.kr \\ Keywords: Sur8; fibroblast growth factor-2; protein kinase $C \alpha / \delta$; Ras signaling; colorectal cancer \\ Received: July 15, $2017 \quad$ Accepted: December 03, $2017 \quad$ Published: December 14, 2017 \\ Copyright: Lee et al. This is an open-access article distributed under the terms of the Creative Commons Attribution License 3.0 \\ (CC BY 3.0), which permits unrestricted use, distribution, and reproduction in any medium, provided the original author and source \\ are credited.
}

\section{ABSTRACT}

Scaffold proteins of the mitogen activated protein kinase (MAPK) pathway recruit protein kinase cascades to confer context-specificity to cellular signaling. Varying concentrations of scaffold proteins determine different aspects of signaling outputs. However, regulatory mechanisms of scaffold proteins are poorly understood. Sur8, a scaffold protein in the Ras-MAPK pathway, is known to be involved in cell transformation and migration, and is increased in human colorectal cancer (CRC) patient tissue. Here we determine that regulation of Sur8 stability mediates transformation and migration of CRC cells. Fibroblast growth factor 2 (FGF2) is identified as an external regulator that stabilizes Sur8. Protein kinase C-alpha and -delta $\left(\mathrm{PKC}_{\alpha} / \delta\right)$ are also identified as specific mediators of FGF2 regulation of Sur8 stability. PKC $\alpha / \delta$ phosphorylate Sur8 at Thr-71 and Ser-297, respectively. This phosphorylation is essential for polyubiquitin-dependent degradation of Sur8. Sur8 mutations, which mimic phosphorylation by $\mathrm{PKC} \alpha / \delta$ and destabilized Sur8, suppress the FGF2-induced transformation and migration of CRC cells. The clinical relevance of Sur8 regulation by $\mathrm{PKC} \alpha / \delta$ is indicated by the inverse relationship between $P K C \alpha / \delta$ and Sur8 expression in human CRC patient tissues. Overall, our findings demonstrate for the first time a regulatory mechanism of Sur8 stability involving cellular transformation and migration in CRC.

\section{INTRODUCTION}

Scaffold proteins are key regulators of cellular signaling pathways, which coordinate protein kinase cascades for proper and efficient signal transduction [1-3]. When cells encounter internal or external stimuli, scaffold proteins dynamically translocate to specific cellular locations to serve as physical platforms for the integration of signaling components into a spatially proximate orientation [1, 4]. It is recognized that regulations of scaffold proteins, especially regulating their concentrations, are crucial for the modulation of highly complex signaling networks. Various cellular states can be induced depending on the precise expression of scaffold proteins $[2,5]$. Therefore, scaffold proteins require tight regulation of their expression levels to control complex physiological events.

The MAPK pathway which includes extracellular signal-regulated kinase (ERK), Jun N-terminal kinase (JNK), and p38, plays important roles in controlling cellular physiologies [6]. The Ras-ERK pathway has been implicated in fundamental cellular processes including cell growth, survival, and migration [7, 8]. Scaffold proteins in the Ras-ERK pathway function to modulate signaling intensity and duration in order to produce different cellular behaviors. 
Suppressor of Ras-8 (Sur8), a scaffold protein of the Ras-ERK pathway, has been shown to be involved in cell growth, transformation, and migration via interaction with Ras and Raf $[9,10]$. Increased Sur8 levels positively regulate Ras-mediated cellular processes. However, the mechanisms controlling Sur8 cellular levels have not yet been revealed.

In this study, fibroblast growth factor 2 (FGF2), a marker of epithelial to mesenchymal transition (EMT) and metastases [11, 12], is identified as a factor responsible for stabilizing Sur8. We investigate subsequent effects of FGF2-mediated Sur8 stabilization on transformation and migration of CRC cells. Sur8 stabilization contributes specifically to transformation and migration, but not normal growth, of CRC cells, mediated by FGF2. Amino acid sequence analyses of Sur8 raise the possibility that protein kinase C (PKC) might be involved in Sur8 phosphorylation. PKC-alpha and $\mathrm{PKC}$-delta $(\mathrm{PKC} \alpha / \delta)$ are identified as specific kinases which phosphorylate Sur8. The stabilization of Sur8 by FGF2 is accomplished through $\mathrm{PKC} \alpha / \delta$ protein reduction, and the pathological relevance to the reverse regulation of Sur 8 and $\mathrm{PKC} \alpha / \delta$ by FGF2 is observed through the inverse relationship between Sur8 and $\mathrm{PKC} \alpha / \delta$ protein levels in CRC patient tissue. We further characterize $\mathrm{PKC} \alpha / \delta$ phosphorylation of Sur8 at Thr-71 and Ser297 by generating mutants for these phosphorylation sites. Our results reveal that phosphorylation of Sur8 is essential for its degradation and subsequent suppression of cell transformation and migration. Overall, this study provides a novel mechanism for Sur8 stabilization by FGF2 signaling resulting in transformation and migration of CRC cells.

\section{RESULTS}

\section{FGF2 stabilizes Sur8 via inhibition of polyubiquitination-dependent proteasomal degradation}

To identify a physiological signaling factor controlling Sur8, we tested the effects of several growth factors on Sur8 levels in human embryonic kidney 293 (HEK293) cells. FGF2, and to a lesser degree epidermal growth factor (EGF), increased Sur8 protein levels without changing Sur8 mRNA levels (Supplementary Figure 1A). FGF2 was more effective in stabilizing Sur8 as confirmed by a time-course analysis (Supplementary Figure 1B). We thus selected FGF2 for further investigation of its regulatory mechanisms of Sur8 stabilization. With FGF2 treatment, Sur8 levels increased, together with ERK activation, in a timeand concentration-dependent manner (Figure 1A and 1B). The increase in Sur8 levels, as well as the ERK activation by FGF2, was abolished with the addition of PD166866, an FGF2 specific inhibitor, as shown by both immunoblot (Figure 1C) and immunocytochemical analyses (Figure 1D and 1E). The effect of FGF2 inhibition on Sur8 stability was further confirmed by using another FGFR inhibitor, AZD4547 (Supplementary Figure 2). By treatment with cycloheximide, Sur8 levels were maintained up to 12 hours in the presence of FGF2. However, co-treatment with PD166866 substantially reduced the half-life of Sur8 (Figure $1 \mathrm{~F}$ and $1 \mathrm{G}$ ). FGF2-mediated Sur8 stabilization was attributed to the inhibition of the proteasomal degradation of Sur8 via suppression of its K48-linked polyubiquitination, as demonstrated by effects of MG132 (Figure 1H) and a ubiquitination assay (Figure 1I).

\section{Regulation of Sur8 stability is involved in FGF2- induced transformation and migration of CRC cells}

We have previously observed overexpression of Sur8 in CRC patient tissues, as well as CRC cell lines, and identified a role of Sur8 in growth, transformation, and migration of CRC cells [13]. To investigate whether Sur8 stabilization by FGF2 is involved in neoplastic behavior of CRC cells, we first tested effects of FGF2 on Sur8 stability in DLD-1 human CRC cell line. As similarly observed in HEK293 cells (Supplementary Figure 1A), FGF2 was shown most effective one among the tested growth factors, and led to gradual increases in Sur8 stability, together with ERK activation in a timeand concentration-dependent manner (Supplementary Figure 3A-3C). We next examined whether Sur8 mediates FGF2-induced cellular responses by using DLD-1 and SW480 CRC cell lines having Sur8 knockout (KO) or overexpression (OE). ERK activities in Sur8-KO DLD1 cells were substantially lower, compared with those in the corresponding parental DLD-1 cells, which express high levels of endogenous Sur8. The low ERK activity observed in Sur8-KO cells was only marginally restored by the addition of FGF2 (Figure 2A). However, basal ERK activity was significantly increased by Sur8-OE in SW480 cells, which express lower level of endogenous Sur8. The ERK activity was further increased by FGF2 treatment in Sur8-OE SW480 cells (Figure 2A). The observed increase in cell proliferation with FGF2 treatment in both Sur8-KO DLD-1 and Sur8-OE SW480 cells were not significantly different from that observed in parental cells (Figure 2B). However, FGF2-induced transforming potential was significantly reduced by Sur8$\mathrm{KO}$, and increased with Sur8-OE in DLD-1 and SW480 cells, respectively (Figure 2C). Similar effects of Sur8$\mathrm{KO}$ and Sur8-OE were also observed in migration assays (Figure 2D). Overall, Sur8 stabilization plays a major role in FGF2-induced transformation and migration of CRC cells, without affecting the normal growth. 


\section{PKC $\alpha$ and PKC $\delta$ mediate the FGF2-induced stabilization of Sur8}

To further explore the underlying mechanisms of FGF2-induced Sur8 stabilization, we searched the database NetPhos 2.0 and found several putative phosphorylation sites on Sur8 (Supplementary Figure 4A). Moreover, PKC was suggested as the most potential kinase for the phosphorylation of Sur8 by NetPhos 3.1 sequence analysis (Supplementary Figure 4B). We tested if $\mathrm{PKC}$ regulates Sur8 stability by treatment with a panPKC inhibitor (Ro 31-8220), a classical PKC inhibitor (Gö6976), or a $\mathrm{PKC} \delta$ specific inhibitor (rottlerin) in HEK293 cells. We observed an increase in Sur8 levels with inhibitor treatment (Supplementary Figure 5A-5C). Conversely, reduction of Sur8 levels was observed when PKC was activated by phorbol 12-myristate 13-acetate (PMA) (Supplementary Figure 5D). Furthermore, overexpression of $\mathrm{PKC} \alpha$ and $\mathrm{PKC} \delta$, but not $\mathrm{PKC} \varepsilon$ or $\mathrm{PKC}$, reduced Sur8 levels (Figure 3A). The importance of PKC $\alpha$ and PKC $\delta$ (together denoted PKC $\alpha / \delta$ ) in Sur8 destabilization was further indicated by an increase of Sur8 levels after specific knockdown of these kinases (Figure 3B).

It is known that PKCs are activated by FGF2 [14]. Intriguingly, levels of $P K C \alpha / \delta$ were specifically reduced during time-course treatment with FGF2 in HEK293 cells (Figure 3C). The reduction of $\mathrm{PKC} \alpha / \delta$ by
A

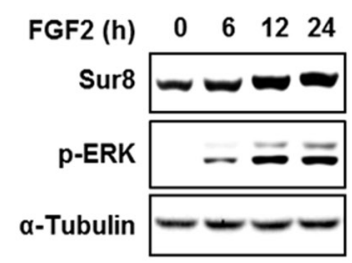

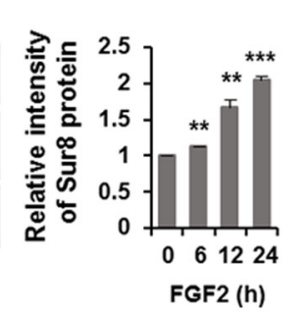

B

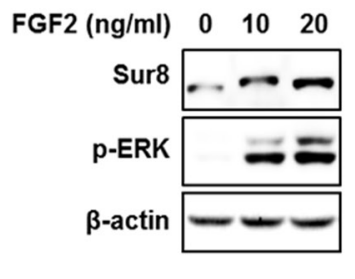

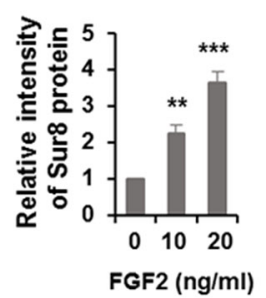

C

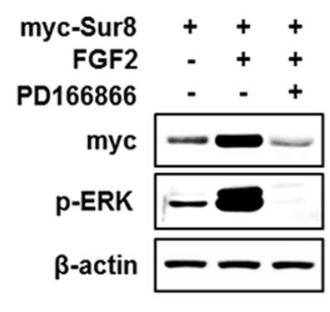

D

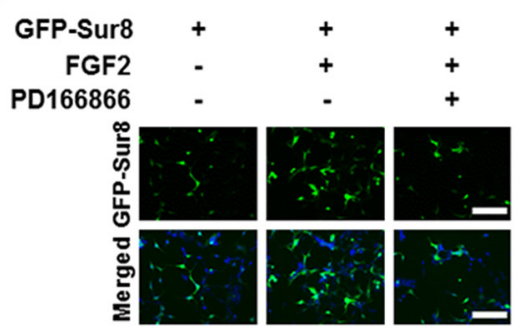

E

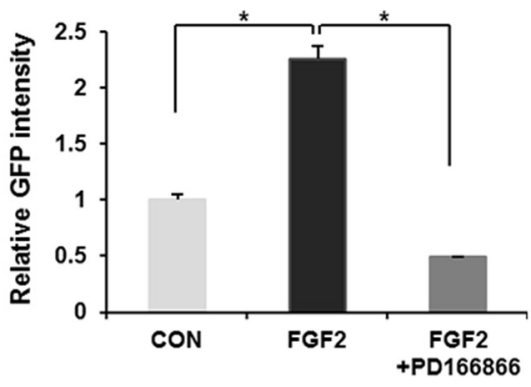

$\mathbf{F}$

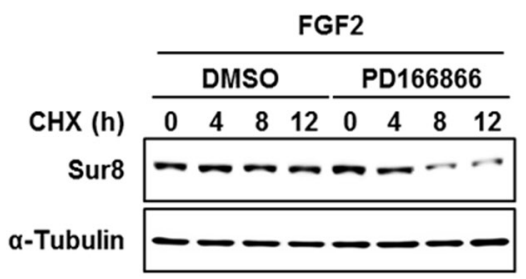

G

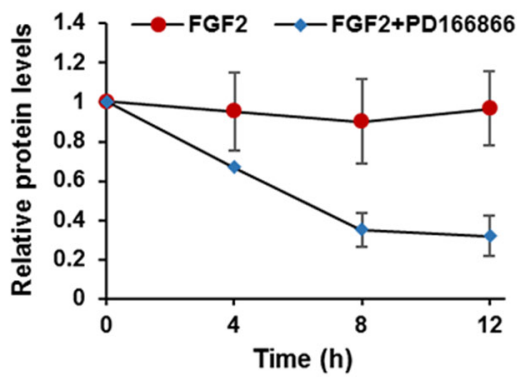

H

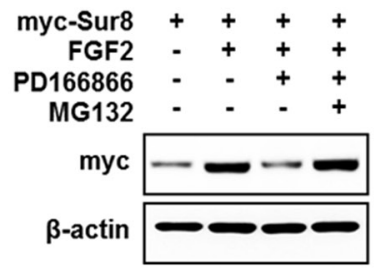

I

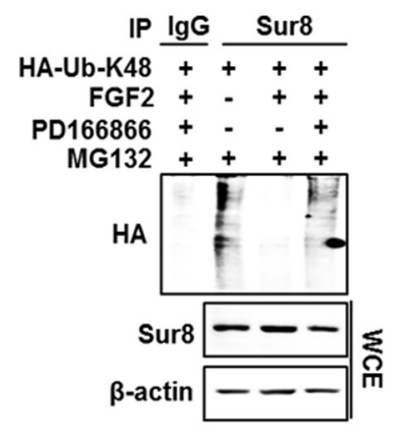

Figure 1: FGF2 stabilizes Sur8 via inhibition of polyubiquitination-dependent proteasomal degradation. (A, B) HEK293 cells were treated with FGF2 in a time- (A) and dose- (B) dependent manner. (C, D) Cells were transfected with myc-tagged (C) or GFPtagged (D) Sur8 plasmid. At 24 hours post-transfection, cells were treated with FGF2 $(20 \mathrm{ng} / \mathrm{mL})$ for 24 hours, followed by 2-hour pretreatment with DMSO or a specific FGFR1 inhibitor, PD166866 (100 nM). Representative fields of GFP-positive cells (upper panel) and merged GFP and DAPI (lower panel) are shown (D). Scale bars, $500 \mu \mathrm{m}$. (E) Quantified data are shown in graph with mean \pm SD from three independent experiments. ${ }^{*} P<0.05$. (F, G) Measurement of Sur8 turnover rate by a CHX chase assay. Cells were treated with $50 \mu \mathrm{g} /$ $\mathrm{mL}$ CHX and with FGF2 alone or plus PD166866 for the indicated time periods. The Sur8 protein levels were examined by immunoblot (F) and quantitated (G). (H, I) Cells were transfected with myc-tagged Sur8 (H) or together with HA-tagged K48 ubiquitin (HA-Ub-K48) (I) and treated as indicated for 24 hours followed by $20 \mu \mathrm{M} \mathrm{MG132} \mathrm{treatment} \mathrm{for} 4$ hours before harvesting. Whole cell extracts (WCEs) were immunoprecipitated with an immunoglobulin G (IgG) control or Sur8 antibody (I). WCEs were subjected to immunoblot analysis using the indicated antibodies (A-C, F, H-I). 
FGF2 occurred at the protein level, as observed by the absence of change in mRNA levels of all PKC isotypes upon FGF2 treatment (Figure 3D). Consistently, the specific reduction of $\mathrm{PKC} \alpha / \delta$ by $\mathrm{FGF} 2$ correlated with FGF2-induced increase of $\mathrm{PKC} \alpha / \delta$ binding affinity to Sur8 after MG132 treatment (Figure 3E). This reduction can be attributed to polyubiquitin-dependent proteasomal degradation as shown by a ubiquitination assay (Figure 3F). Moreover, overexpression and knockdown of $\mathrm{PKC} \alpha / \delta$ abolished the effect of FGF2 on Sur8 stabilization (Figure $3 \mathrm{G}$ and $3 \mathrm{H}$ ). In addition, even though both FGF2 and EGF were shown to increase Sur8 stability (Supplementary Figures 1A and 3A), overexpression of $\mathrm{PKC} \alpha / \delta$ was able to block FGF2induced Sur8 stabilization only, indicating the specific roles of $\mathrm{PKC} \alpha / \delta$ in mediating FGF2 regulation of Sur8 (Supplementary Figure 6A and 6B).

A
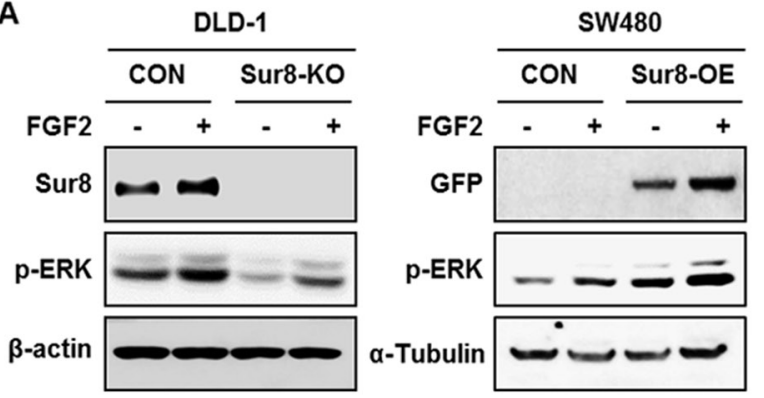

C
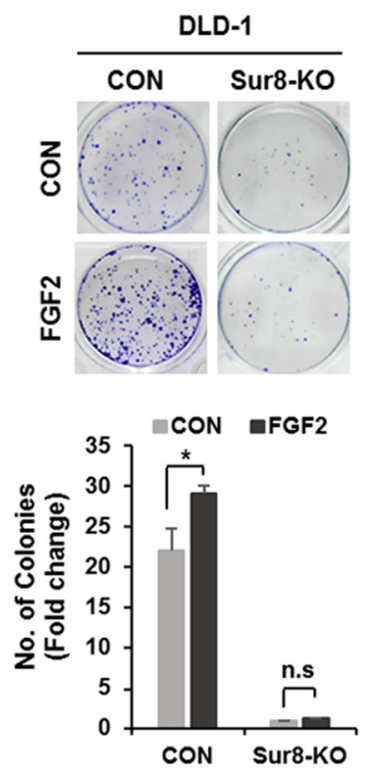
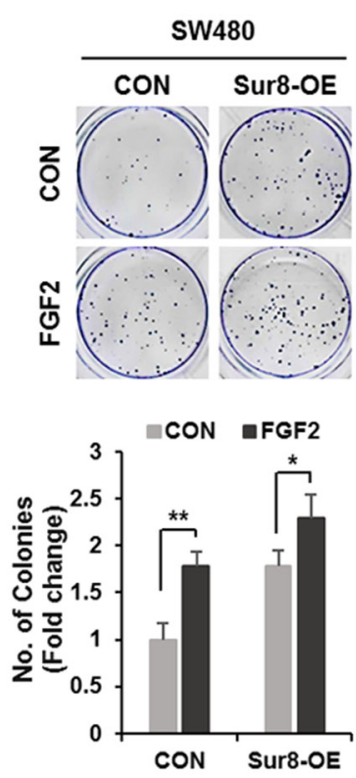

$\mathrm{PKC \alpha / \delta}$ promotes Sur8 degradation through phosphorylation of Thr-71 and Ser-297, respectively

To examine whether Sur8 is a direct substrate of $\mathrm{PKC} \alpha / \delta$, we performed in vitro kinase assays using GSTfused PKC $\alpha$ and PKC $\delta$ (GST-PKC $\alpha$ and GST-PKC $\delta$ ), and Sur8 recombinant protein. As shown by the assays, $\mathrm{PKC} \alpha / \delta$ phosphorylated Sur8, together with their autophosphorylation. (Figure 4A). Thr-71 and Ser-297 were identified as the $\mathrm{PKC} \alpha / \delta$ phosphorylation sites on Sur8 by LC/MS-MS analysis (Figure 4B and 4C). These phosphorylation sites are well conserved across species (Supplementary Figure 7). Moreover, comparison of the amino acid sequence of human Sur8 with that of other $\mathrm{PKC} \alpha / \delta$ substrates revealed that Sur8 possesses PKC consensus sequences similar to those of other $\mathrm{PKC} \alpha / \delta$ substrates (Supplementary Figure 8).

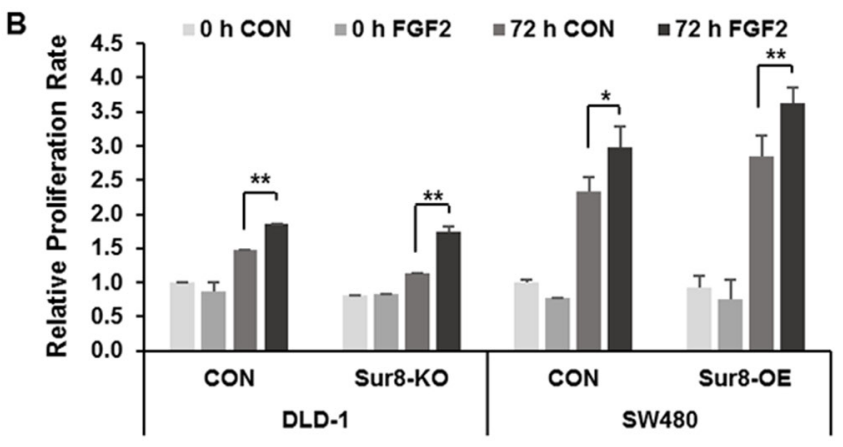

D

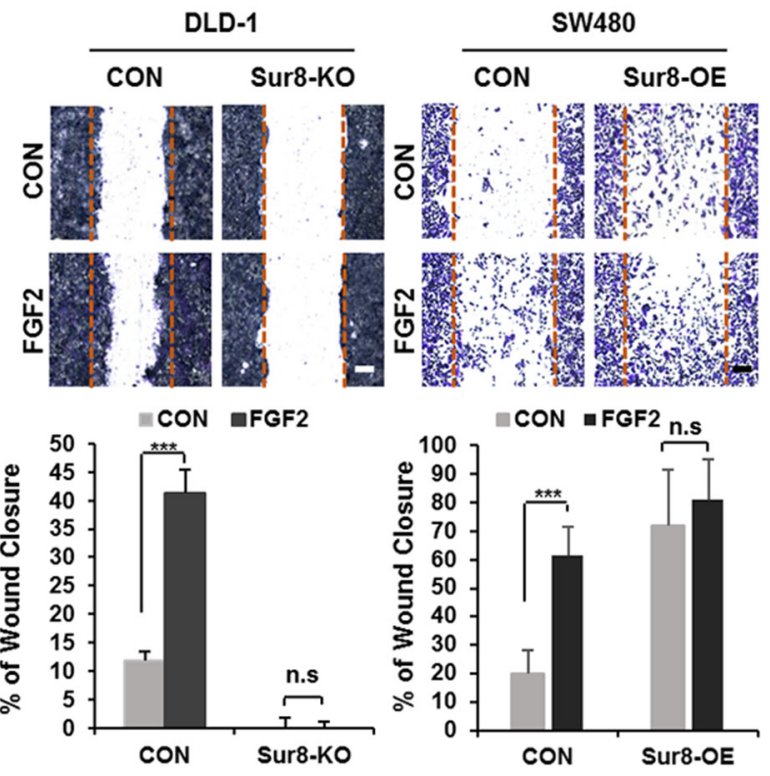

Figure 2: Effects of Sur8 level on FGF2-induced cellular transformation and migration. (A) DLD-1 control (CON), Sur8knockout (Sur8-KO) cells and SW480-CON, or stably expressing GFP-Sur8 (Sur8-OE) cells were treated with PBS (control) or FGF2 for 24 hours. WCEs were immunoblotted with the indicated antibodies. (B-D) After treating DLD-1 and SW480 cell lines as indicated, bioassays for measuring cell proliferation rate (B), foci-forming ability (C), and migration rate (D) were performed. All graphs represent mean \pm SD of three independent experiments. ${ }^{*} P<0.05,{ }^{* *} P<0.01,{ }^{* * *} P<0.001$. Scale bars, $500 \mu \mathrm{m}$. 
To further explore the regulation of Sur8 stability by phosphorylation, we utilized Sur8 nonphosphorylatable mutants, Sur8-T71A and Sur8-S297A, which cannot be phosphorylated by $\mathrm{PKC} \alpha / \delta$, respectively. As shown by ablation of $\mathrm{PKC} \alpha / \delta$-mediated degradation of the Sur8 nonphosphorylatable mutants, phosphorylation of Sur8 at Thr-71 and Ser-297 plays a critical role in its degradation (Figure 4D and 4E). Sur8-T71A, and to a greater extent Sur8-S297A, both substantially reduced the polyubiquitination of Sur8 by PKC $\alpha / \delta$ (Figure $4 \mathrm{~F}$ and 4G). Moreover, these phosphorylation sites are important for FGF2-induced Sur8 stabilization, as demonstrated by a comparably lower increase in levels of Sur8-T71A and -S297A after FGF2 treatment (Figure 4H). Together, Thr71 and Ser-297 are essential residues for regulation of Sur8 stability by $\mathrm{PKC} \alpha / \delta$ and FGF2 signaling.

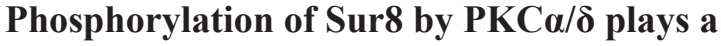 critical role in transformation, migration, and invasion of CRC cells}

To characterize the importance of the $\mathrm{PKC} \alpha / \delta$ phosphorylation of Sur8 in the FGF2-mediated cellular processes of CRC cells, we generated cell lines with wild type Sur8 (DLD-Sur8-WT) or phosphomimetic mutants (DLD-Sur8-T71E and DLD-Sur8-S297D) rescued in DLD-1 Sur8-KO cell lines (DLD-Sur8-KO). As shown by immunoblot (Supplementary Figure 9A) and immunocytochemical (Supplementary Figure 9B and 9C) analyses, Sur8 stability was lower in DLD-Sur8-T71E and DLD-Sur8-S297D cells compared with DLD-Sur8-WT cells. Only marginal effects on Sur8 stability in DLDSur8-T71E and DLD-Sur8-S297D cells were observed with stimulation by FGF2 or inhibition of FGF2 by

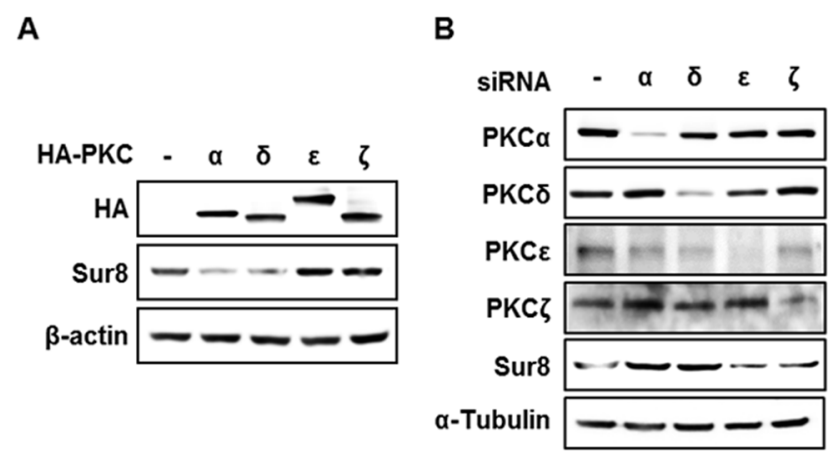

C

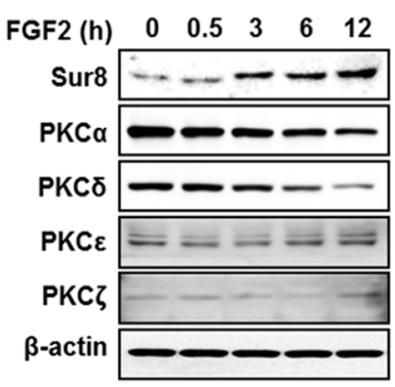

D

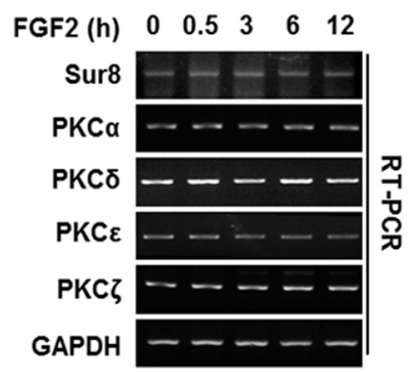

E

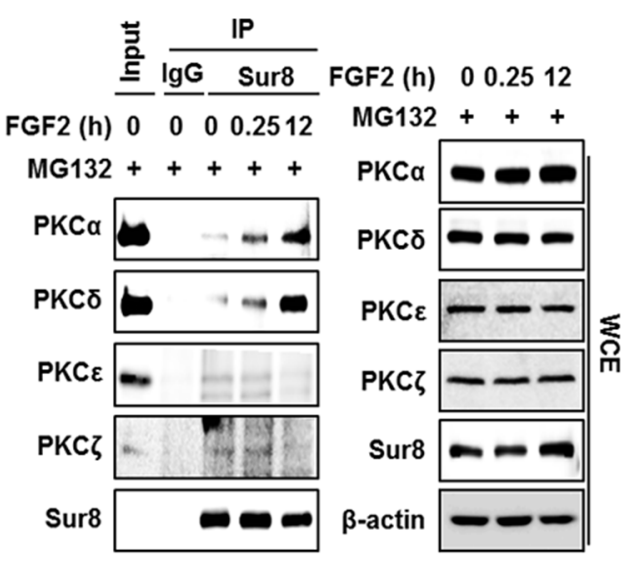

$\mathbf{F}$

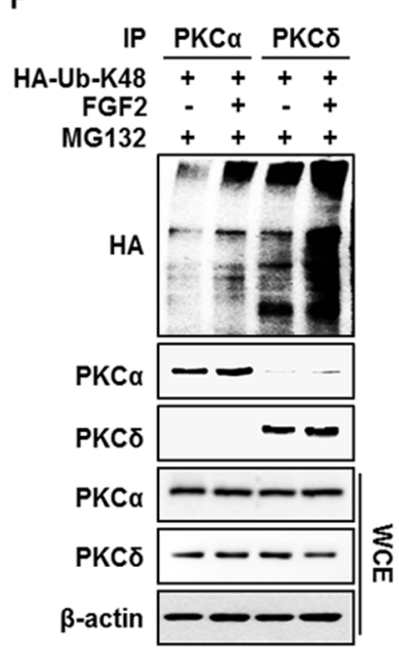

G

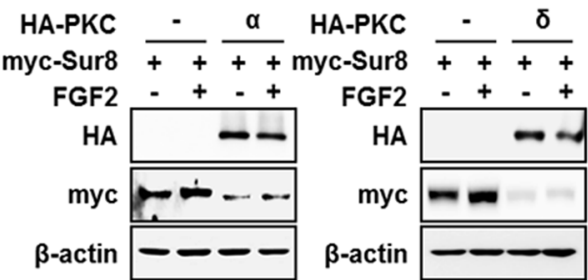

H

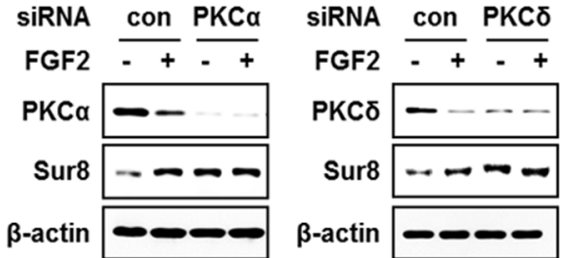

Figure 3: FGF2 stabilizes Sur8 through destabilization of PKCa and PKC $\boldsymbol{\text { P }}$. (A, B) HEK293 cells were transfected with 0.5 $\mu \mathrm{g}$ of HA-tagged PKC $\alpha, \delta$, $\varepsilon$, or $\zeta$ in (A) and with $20 \mathrm{nMsiRNAs}$ against PKC $\alpha, \delta$, $\varepsilon$, or $\zeta$ in (B). (C, D) Time-course stimulation of FGF2. Protein levels (C) and mRNA levels (D) of Sur8 and PKC isotypes were assessed by immunoblot and RT-PCR, respectively. (E) FGF2dependent interaction of Sur8 with PKC $\alpha / \delta$. Cells were treated with FGF2 for the indicated time and MG132 for 4 hours before WCEs were collected for immunoprecipitation with either IgG control or anti-Sur8 antibody. (F) Cells were transfected withHA-Ub-K48 plasmid and treated with FGF2 for 12 hours and MG132 for 4 hours as indicated. WCEs were immunoprecipitated with anti-PKC $\alpha$ or PKC $\delta$ antibody. $(\mathbf{G}, \mathbf{H})$ Effects of $\mathrm{PKC} \alpha / \delta$ OE or KD on FGF2-mediated Sur8 stabilization. Cells were transfected with the indicated plasmids or siRNAs and treated with or without FGF2 for 24 hours at 24 hours post-transfection. WCEs were subjected to immunoblot analysis (A-C, E-H). 
PD166866 (Supplementary Figure 9B and 9C). The focusforming ability in DLD-Sur8-T71E and DLD-Sur8-S297D cells was also critically lower than in DLD-Sur8-WT cells (Figure 5A). Consistent with the no effect of Sur8-KO on FGF2-induced cell growth (Figure 2B), the growth rates in DLD-Sur8-T71E and DLD-Sur8-S297D cells were indistinguishable from that in DLD-Sur8-WT cells, regardless of FGF2 stimulation (Figure 5B). However, the effects of Sur8 on anchorage-independent cell growth, migration, and invasion rates were noteworthy. In DLDSur8-T71E and DLD-Sur8-297D cells, lower anchorageindependent cell growth, migration, and invasion were all observed, even with FGF2 stimulation (Figure 5C-5E). A concurrent increase in the protein levels of the epithelial cell maker E-cadherin, and reduction in the protein levels of the mesenchymal marker Snail and the mRNA levels of matrix metalloproteinase (MMP)-2 and MMP-9 were observed (Figure 5F).

We further evaluated the effect of blocking $\mathrm{PKC} \alpha / \delta$ phosphorylation of Sur8 by using SW480 cells expressing the nonphosphorylatable Sur8 mutations (SW-Sur8-T71A or SW-Sur8-S297A). Both transforming and migratory potential, though not normal growth, were higher in SW-Sur8-T71A and SW-Sur8-S297A cells compared to SW-Sur8-WT cells, without further effects of FGF2 (Supplementary Figure 10A-10C). Also, increased levels
A

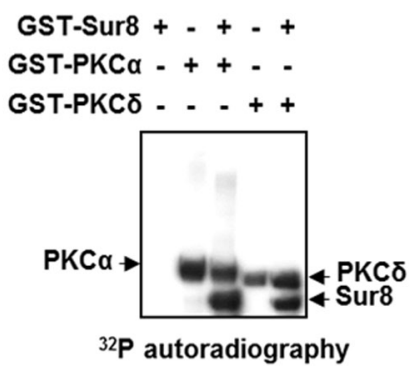

D

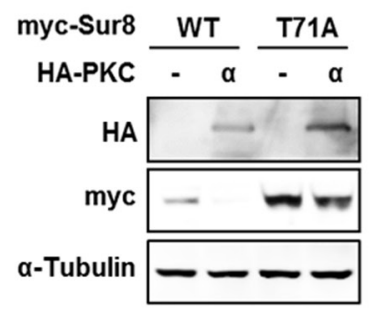

B

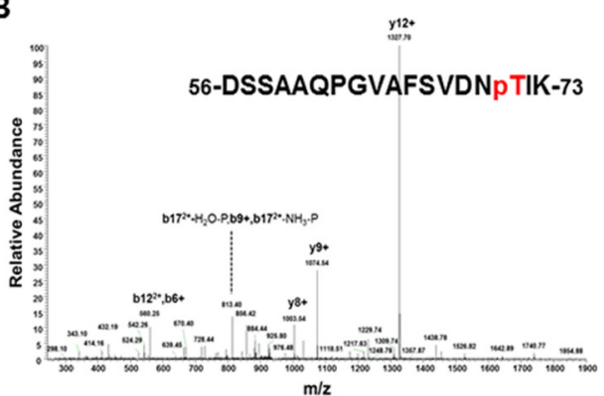

E

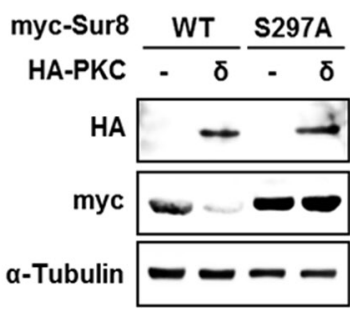

H

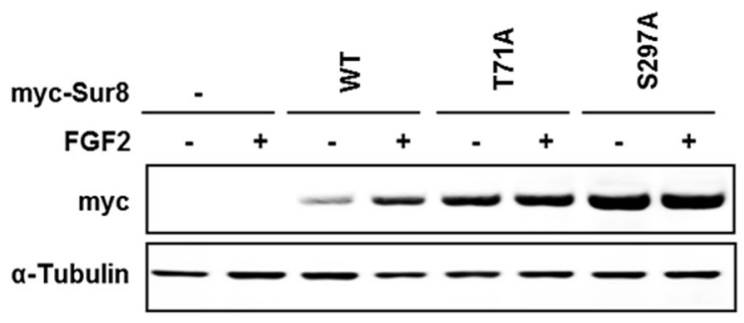

C

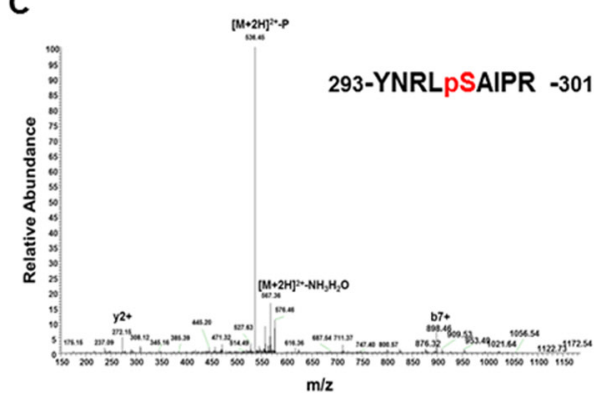

G

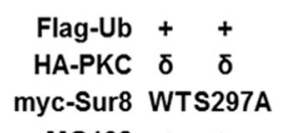

MG132 + +

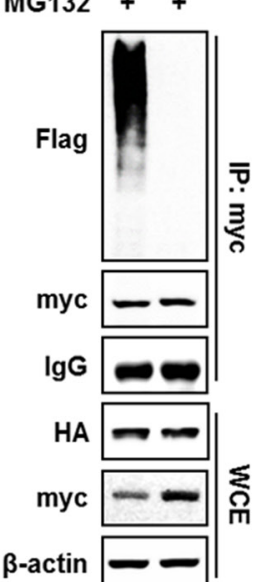

Figure 4: Phosphorylation of Sur8 at Thr71 and Ser297 by PKCa and PKCס, respectively, are responsible for Sur8 degradation. (A) Autoradiography of in vitro kinase assays with recombinant GST-Sur8, GST-PKC $\alpha$, or GST-PKC $\delta$ alone, or GSTSur8 plus GST-PKC $\alpha$ or GST-PKC $\delta$. Autophosphorylated PKC $\alpha$ and $\mathrm{PKC} \delta$ proteins, and phosphorylated Sur8 proteins are indicated. (B, C) Identification of phosphorylation sites of Sur8 by liquid chromatography tandem-mass spectrometry (LC-MS/MS). Graphs show representative mass spectrum of Sur8 depicting mass/charge $(\mathrm{m} / \mathrm{z})$ of identified PKC $\alpha(\mathrm{B})$ or PKC $\delta(\mathrm{C})$ phosphorylation sites. Spectra of the phosphopeptides in the digested Sur8 protein are shown. (D, E) Effects of nonphosphorylatable mutations of Sur8 on PKC $\alpha$ or PKC $\delta$ regulation of its stability. HEK293 cells were transfected with $1 \mu \mathrm{g}$ of myc-Sur8-WT, myc-Sur8-T71A or myc-Sur8-S297A plasmid with or without HA-PKC $\alpha$ (D) or HA-PKC $\delta$ (E) plasmid. (F, G) Nonphosphorylatable mutation of T71 or S297 reduces Sur8 ubiquitination. Cells were transfected in the combinations of plasmids as indicated, followed by MG132 treatment for 4 hours before WCEs were immunoprecipitated with anti-myc antibody. (H) Cells were transfected with Sur8 nonphosphorylatable mutants and treated with FGF2 as indicated. WCEs were subjected to immunoblot analysis using the indicated antibodies (D-H). 
of Snail protein corresponded to the increased migratory potential of SW-Sur8-WT and mutant cells, as shown by immunoblot analysis (Supplementary Figure 10D). Overall, the PKC $\alpha / \delta$ phosphorylation sites on Sur8 are critical for promoting Sur8-mediated and FGF2-regulated transformation, wound closure, and invasion.

\section{Low $\mathrm{PKC} \alpha / \delta$ expression correlates with elevated Sur8 levels in human CRC}

$\mathrm{PKC} \alpha / \delta$ can exhibit different functions, either promoting or suppressing tumorigenesis in different cancer types [15]. In CRC, loss of $\mathrm{PKC} \alpha$ or $\mathrm{PKC} \delta$ promotes cell proliferation and transformation in vitro [16-18]. To investigate the clinical relevance of $\mathrm{PKC} \alpha / \delta$ regulation of
Sur8 stabilization, we analyzed 13 sets of patient-matched tumor and adjacent normal tissue samples from human CRC. Immunohistochemical (IHC) analysis of these tissues revealed that Sur8 levels were higher in 9/13 (69.2\%) CRC patient tumors compared with their adjacent normal tissue, whereas $\mathrm{PKC} \alpha$ and $\mathrm{PKC} \delta$ expression appeared lower in 11/13 (84.6\%) and 8/13 (61.5\%) of CRC tumors, respectively (Figure 6A-6D). Comparison of the protein expression ratios (tumor/normal) of Sur8, $\mathrm{PKC} \alpha$, and $\mathrm{PKC} \delta$ from corresponding regions of patient-matched tumor and normal tissues further revealed significant negative correlations of Sur8 with both PKC $\alpha(P=0.0008)$ and $\mathrm{PKC} \delta(P=0.0015)$ (Figure 6E). Thus, there are significant association between Sur8 and $\mathrm{PKC} \alpha / \delta$ levels in human CRC.
A

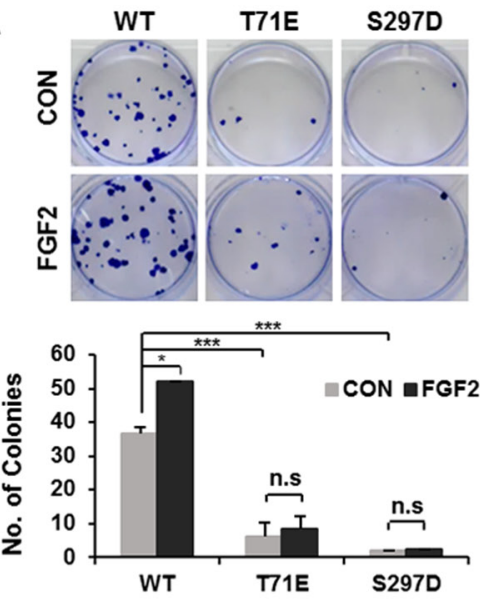

D

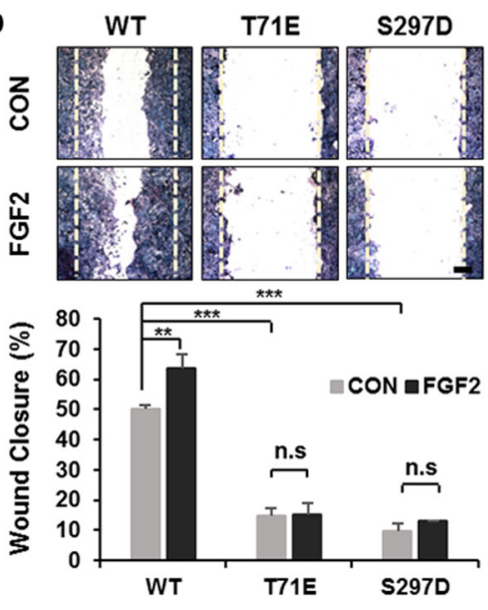

B

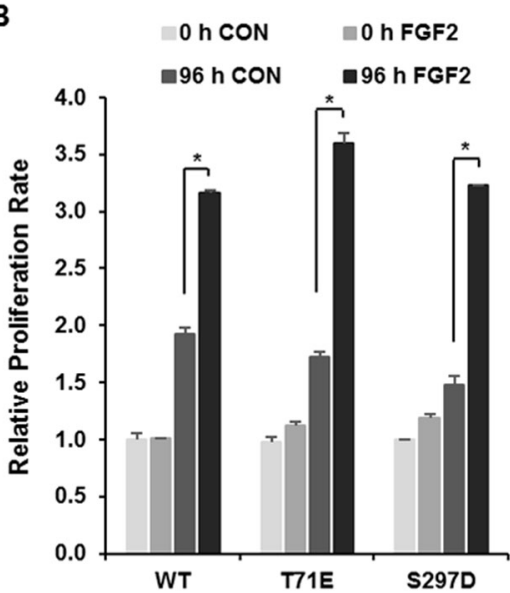

E

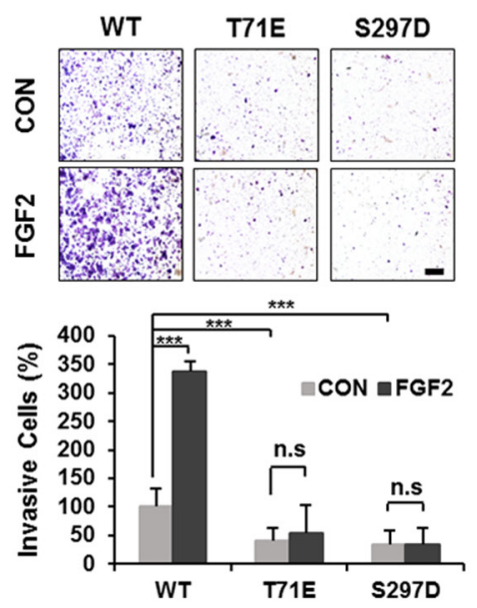

C
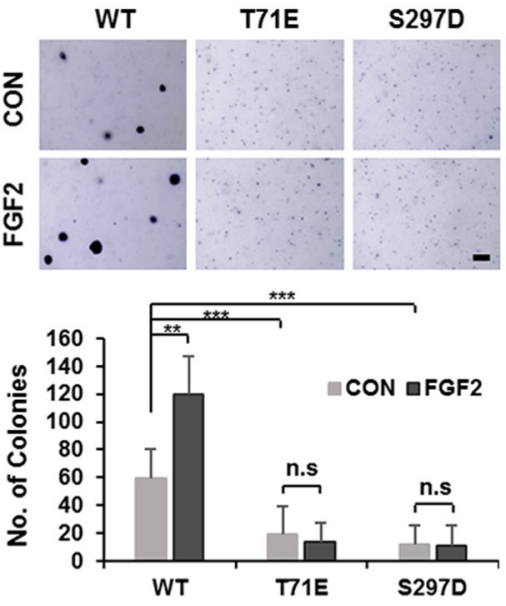

$F$

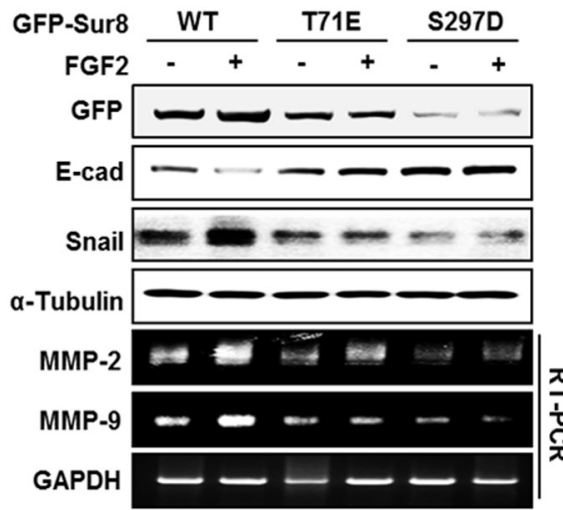

Figure 5: Wild-type Sur8, but not phosphomimetic mutations, mediates FGF2-induced cellular transformation, migration, and invasion. (A-F) GFP-Sur8-WT, GFP-Sur8-T71E, or GFP-Sur8-S297D which were rescued in DLD-1 Sur8-KO cells were treated with PBS (control) or FGF2 and assessed for transformation, proliferation, migration, and invasion potential, and were subjected to immunoblot and RT-PCR analyses. Foci-forming assays were conducted for 2 weeks. Quantifications of colony number are shown in (A). Normal (B) and anchorage-independent (C) cell growth rates were determined by MTT and soft agar assays, respectively. Cells were scratched and allowed for wound closure for 48 hours after treatment with or without FGF2. Representative images of wound closure and quantification of relative wound closure efficiency are shown in (D). Invasion assays were performed using matrigel-coated chambers, and the relative quantification of invaded cells were measured as shown (E). Colonies and cells were stained with crystal violet (A, C-E). Statistical values were ${ }^{*} P<0.05,{ }^{* *} P<0.01,{ }^{* * *} P<0.001$. Scale bars, $500 \mu \mathrm{m}$. WCEs were subjected to immunoblot analysis and total RNAs were subjected to RT-PCR analysis (F). 


\section{DISCUSSION}

Despite advances in the development of cancer therapeutics, current therapeutic strategies still require promising new targets capable of modulating key oncogenic proteins $[19,20]$. Genetic alterations in $R A S$ and $B R A F$ are the driver mutations in cancer which is associated with resistance to current therapies and disease recurrence in various types of cancer, including CRC [21-23]. Emerging studies suggest that targeting the key molecular scaffolding complexes could be a novel therapeutic strategy to overcome current therapy limitations [24].

The scaffold proteins of the Ras/MAPK pathway, including IQGAP1, KSR1, and Sur8, have essential roles in growth, transformation, and migration of cancer cells.
These scaffolding proteins are also more highly expressed in cancer cells than in normal cells. [13, 25-27]. Studies have demonstrated that disrupting the scaffolding functions of IQGAP1 protein deters acquired chemoresistance in Ras-driven tumors [24, 28], and inactivation of KSR by a small molecule inhibitor suppressed oncogenic Ras signaling [29]. Sur8 has been also shown to control tumor growth by affecting anchorage-independent cell growth, without affecting normal growth [10]. These studies suggest the possibility of scaffold proteins as potential ideal targets for cancer therapy.

Varying the expression levels of scaffold proteins is a key to control the kinetics and duration of Ras/MAPK signaling [30]. It is therefore important to understand the molecular mechanisms involved in regulation of these scaffold proteins, which could provide insight into
A

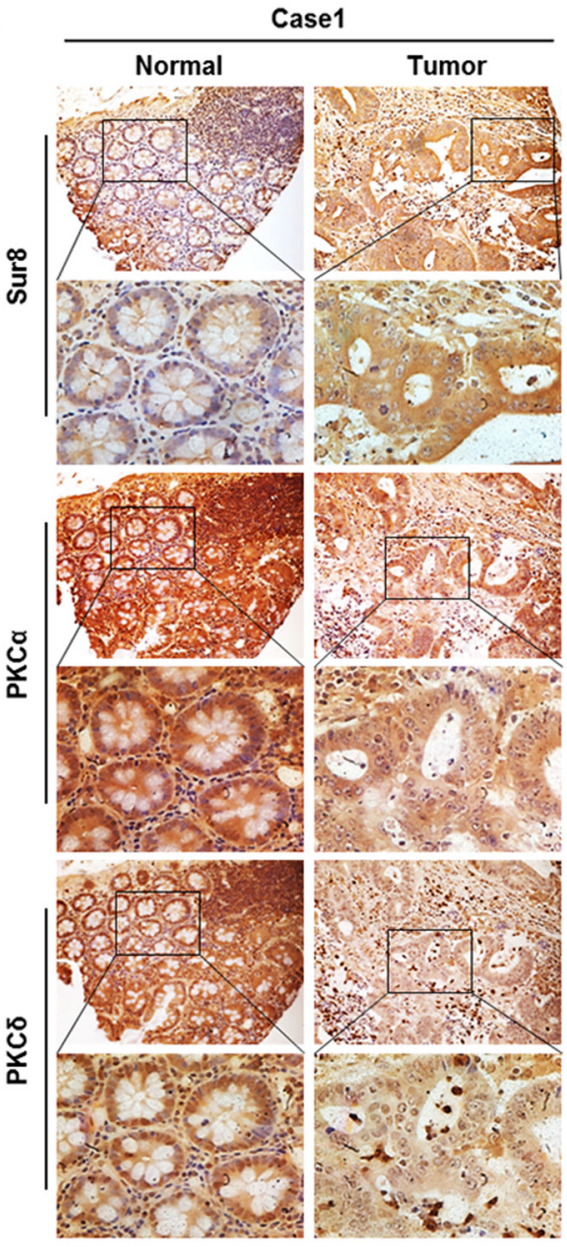

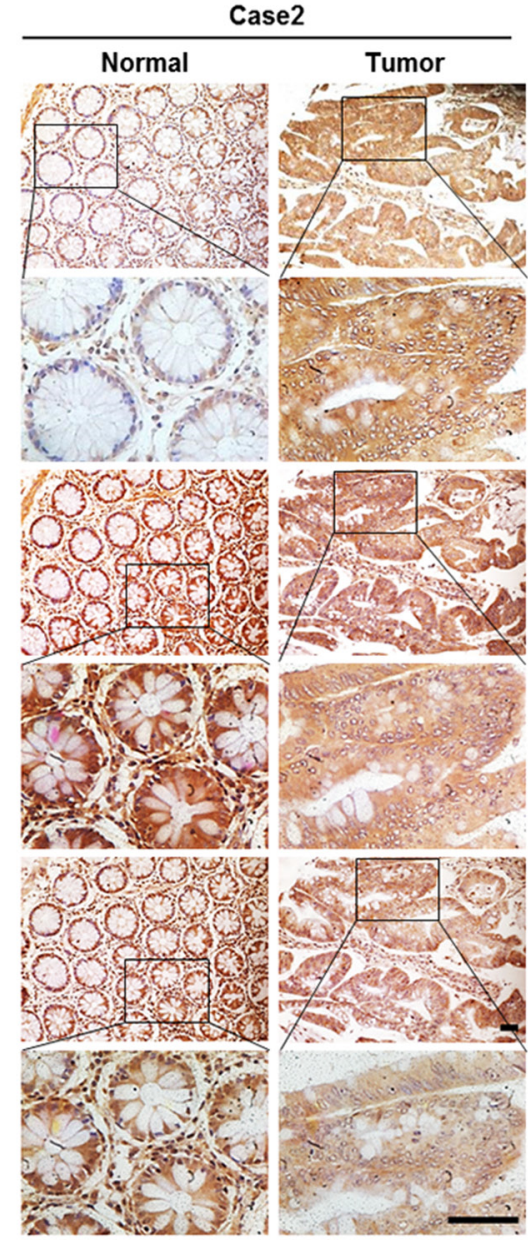

Figure 6: Expression of Sur8, PKCa, and PKC protein in human colorectal normal vs. tumor paired tissues. (A) Normal (left panels) and tumor (right panels) colorectal tissues fixed on TMA slides were analyzed by DAB staining using Sur8 (top panels), PKC $\alpha$ (middle panels), and PKC $\delta$ (bottom panels) antibodies. Representative images are shown at 200× (upper) and 600× (lower) magnifications. Scale bars, $200 \mu \mathrm{m}$. (B-D) Quantitative analysis of Sur8 (B), PKCa (C), and PKC $\delta$ (D) was performed by comparing patient-matched adjacent normal $(n=13)$ colorectal tissue with tumor $(n=26)$ tissue based on H-Score. (E) Graphical image showing the inverse correlation between Sur8 and $\mathrm{PKC} \alpha / \delta$ expression of 13 sets of human colorectal adjacent normal and tumor tissues. All values were calculated using student's $t$-test. ${ }^{*} P<0.05,{ }^{* *} P<0.01,{ }^{* * *} P<0.001$. 
developing novel cancer therapies in Ras-driven tumors. However, the regulatory mechanisms of scaffold proteins, and especially those which determine levels of scaffold proteins, are poorly understood.

We previously determined the functional roles of the Ras/Raf scaffold protein Sur8 in promoting CRC tumorigenesis and metastasis, and also melanomadriven lung metastases via acceleration of Ras signaling activation $[13,25]$. We have identified Sur8 as a potential molecular target for the suppression of oncogenic Ras-driven cancer. Here we provide a mechanistic understanding of Sur8 stabilization by FGF2 through blocking its phosphorylation by $\mathrm{PKC} \alpha / \delta$ (Figure 7).

FGF2 is known to play crucial roles in cell proliferation, transformation, and migration in CRC, though its functional mechanism is poorly understood [11, 31]. Our results show that FGF2 increases Sur8 expression through suppression of K48-linked polyubiquitination of Sur8, indicating that elevated FGF2 levels contributes to stabilizing Sur8. In addition, we show that $\mathrm{PKC} \alpha / \delta$ phosphorylate Sur8, reducing its stability. These results support a tumor suppressive role of $\mathrm{PKC} \alpha / \delta$ in $\mathrm{CRC}$, consistent with recent findings [32]. The functional roles of $\mathrm{PKC} \alpha / \delta$ modulation of Sur8 were further delineated by the inverse regulation of Sur 8 and $\mathrm{PKC} \alpha / \delta$ levels by FGF2, and the inverse expression levels of Sur8 and
$\mathrm{PKC} \alpha / \delta$ in normal and tumor tissues of CRC patients. The reduced expression of $\mathrm{PKC} \alpha / \delta$ we observed in the tumor tissues of CRC patients is consistent with previous findings on reduced $\mathrm{PKC} \alpha / \delta$ expression in human $\mathrm{CRC}$ cell lines and murine intestinal tumors $[17,33]$. Moreover, the role of FGF2 in $\mathrm{PKC} \alpha / \delta$ degradation correlates with a subsequent role of the PKC activator, TPA, in the degradation of PKCs [34]. There is a possibility that activation of FGFR by FGF2 induces an increase of intracellular $\mathrm{Ca}^{2+}$ levels and subsequently activates the known $\mathrm{Ca}^{2+}$-dependent PKC protease, calpain for the proteolysis of PKC [35-37].

Our mutational studies also demonstrate that Sur8 phosphorylation sites are key residues involved in the stabilization of Sur8. We showed that mimicking or blocking the $\mathrm{PKC} \alpha / \delta$ phosphorylation sites on Sur8 controls transformation and migration of CRC cells, including those mediated by FGF2. Notably, there was no effect on FGF2-meidated normal cell growth.

Collectively, our studies provide a novel mechanism for the regulation of Sur8 stability through pathologically relevant FGF2 signaling via degradation of $\mathrm{PKC} \alpha / \delta$. The role of Sur8 in the specific regulation of transformation and migration of CRC cells, without affecting their normal growth, further highlights the importance of Sur8 as a potential target for cancer therapy, especially cancers with Ras mutations.
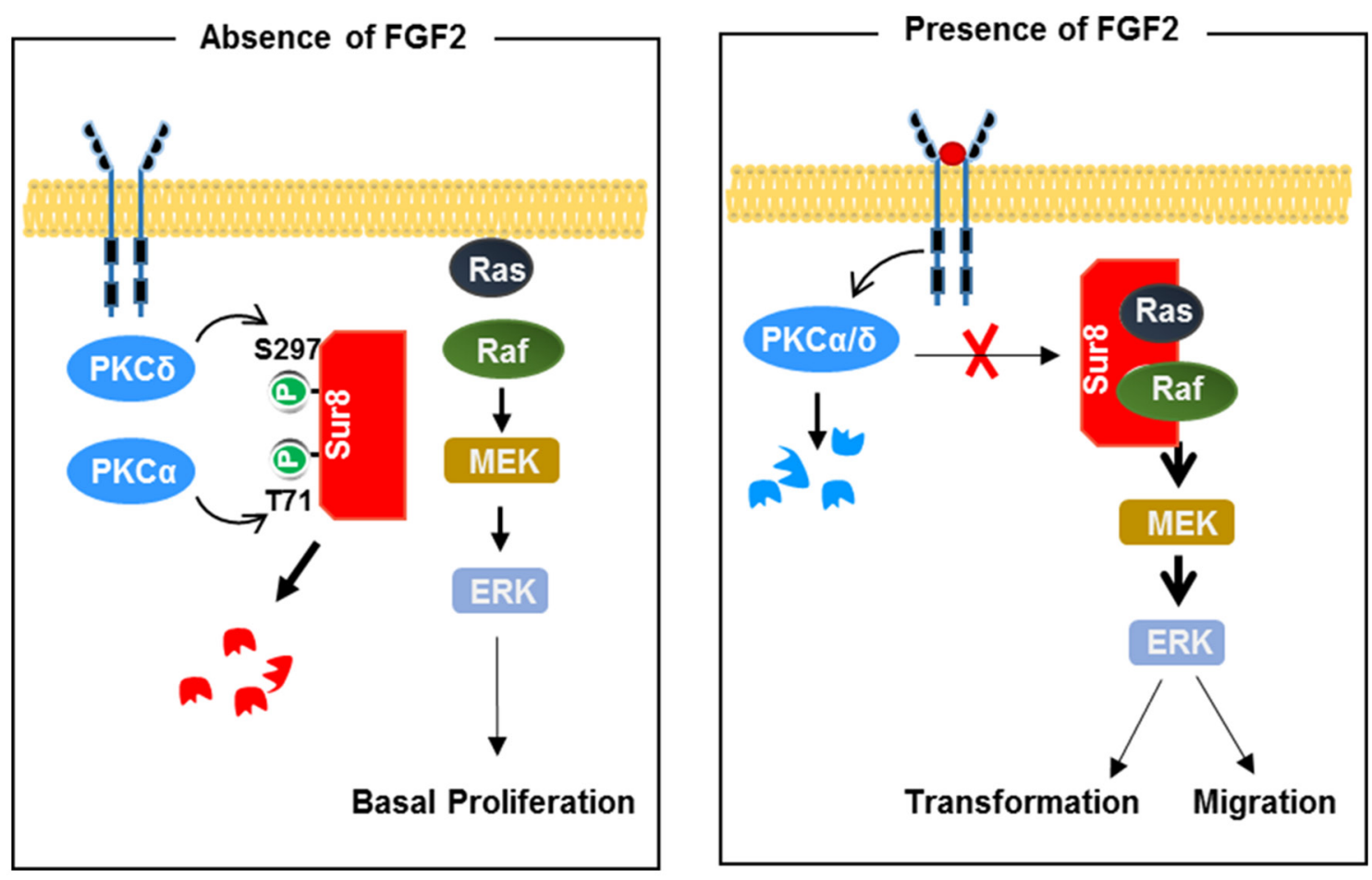

Figure 7: Model for Sur8 stability regulation by FGF2 signaling. In the resting state (left panel), Sur8 is maintained at a low level by PKC $\alpha$ - and PKC $\delta$-mediated phosphorylation at Thr-71 and Ser-297, respectively, and is subsequently degraded. This results in a basal level of cell proliferation. Upon FGF2 stimulation (right panel), Sur8 is maintained at a high level by stabilization through degradation of $\mathrm{PKC} \alpha / \delta$. The stabilized Sur8 promotes transformation and migration of cells via activation of the Ras/ERK pathway. 


\section{MATERIALS AND METHODS}

\section{Cell culture and use of reagents}

HEK293, HEK293T, and human CRC cell lines (DLD-1 and SW480) were purchased from the American Type Culture Collection. The authentication of the cell lines were verified by short tandem repeat (STR) analysis provided by Cosmogenetech (Daejeon, Korea). Cells were propagated at $37^{\circ} \mathrm{C}$ and $5 \% \mathrm{CO}_{2}$ in DMEM (Gibco, Grand Island, NY) or RPMI 1640 (Gibco) supplemented with 10\% FBS (RMBI, Missoula, MA) and 1\% penicillinstreptomycin (Gibco). The following reagents were administered: MG132 $20 \mu \mathrm{M}$ (Calbiochem, San Diego, $\mathrm{CA}$ ); cycloheximide (CHX) and rottlerin $50 \mu \mathrm{g} / \mathrm{mL}$ and $6 \mu \mathrm{M}$, respectively (both from Santa Cruz, Santa Cruz, CA); EGF $20 \mathrm{ng} / \mathrm{mL}$, FGF2 $20 \mathrm{ng} / \mathrm{mL}$, IGF1 $50 \mathrm{ng} / \mathrm{mL}$, and VEGF $20 \mathrm{ng} / \mathrm{mL}$ (all from Peprotech, Rocky Hill, NJ); Gö6976, Ro31-8220, and PD166866 at concentrations of $2.5 \mu \mathrm{M}, 1 \mu \mathrm{M}$, and $100 \mathrm{nM}$, respectively (all from SigmaAldrich, St. Louis, MO); AZD4547 at a concentration of $100 \mathrm{nM}$ (Selleckchem, Houston, TX); and phorbol-12myristate-13-acetate (PMA) at a concentration of $100 \mathrm{nM}$ (Cell Signaling Technologies, Beverly, MA).

\section{Transfection and siRNAs}

Plasmid transfections were performed with Lipofector-EZ (AptaBio, Yongin, Korea) according to the manufacturer's instruction. For transient knockdown of Sur8 and each PKC isozyme in HEK293 cells, siRNA duplexes of Sur8 and PKCs (Bioneer, Daejeon, Korea) were generated and conducted as previously described [25, 38].

\section{Cloning and site-directed mutagenesis}

For generating GFP-tagged Sur8-overexpressing lentiviral plasmids, GFP was inserted into pLVX-IRESHyg vector (\#632185, Clonetech, Palo Alto, CA) at NotI enzyme site prior to cloning Sur8. Human Sur8 complementary DNA (cDNA) was amplified by reverse transcription polymerase chain reaction (RT-PCR) using the following primers: forward 5'-ATAACCGGGATCCA CCATGAGTAGTAGTTTAGGA-3'; reverse 5'-TCTAGA GGATCCGACCATGGCACGATATGG-3'. It was inserted into the pLVX-IRES-Hyg vector expressing GFP after digestion with BamHI (Enzynomics, Daejeon, Korea).

For site-directed mutagenesis, point mutations of Sur8 were introduced by PCR using Pfu DNA polymerase (Invitrogen, Carlsbad, CA). The mutagenic oligonucleotides used for mutagenesis are shown in Supplementary Table 1. PCR reactions were run in the following condition: 15 cycles of 30 seconds at $95^{\circ} \mathrm{C}$, then 1 minute at $54^{\circ} \mathrm{C}$ followed by 10 minutes at $68^{\circ} \mathrm{C}$. The PCR products were digested with $D p n I$ (Enzynomics) for 1 hour for removal of the template plasmids. All mutant plasmids were verified by DNA sequencing (Cosmogenetech).

\section{Establishment of stable cell lines}

To generate Sur8-knockout (KO) DLD-1 cells, DLD1 parental cells were transfected with human Sur8 CRISPR/ Cas9 KO and HDR plasmids (Santa Cruz; sc-409478) according to the manufacturer's instructions, and were selected with puromycin (Sigma-Aldrich) for 2 weeks.

To establish Sur8 rescue cell lines in Sur8-KO cells, HEK293T cells were transfected with pLVX-GFP-Sur8WT, GFP-Sur8-T71E, or GFP-Sur8-S297D, together with the viral packaging psPAX2 and viral envelope pMD2G plasmids at 2:2:1 ratio, respectively, for viral production. Then, Sur8-KO DLD-1 cells were transduced with pLVXGFP-Sur8-WT, GFP-Sur8-T71E, and GFP-Sur8-S297D lentivirus. To make SW480 cells lines stably expressing either Sur8-WT, Sur8-T71A or Sur8-S297A, parental SW480 cells were transduced with pLVX-GFP-Sur8-WT or the mutant lentiviruses. All transduced cell lines were selected with Hygromycin B (Duchefa, Haarlem, The Netherlands) for 2 weeks.

\section{RNA purification and RT-PCR}

Total RNA was prepared and the mRNA levels of Sur8, PKCs, and GAPDH were measured as described previously $[25,38]$. The mRNA levels of MMP-2 and MMP-9 were analyzed using the following primers (Bioneer): $M M P-2$, forward 5'-CTCAGATCCGTGGTGAGATCT-3' and reverse 5'-CTTTGGTTCTCCAGCTTCAGG-3'; $M M P-9$, forward 5'-CAACATCACCTATTGGATCC-3' and reverse 5'-CTGGGTGTAGAGT CTCTCGCT-3'.

\section{Immunocytochemistry, immunoprecipitation, and cellular ubiquitination assays}

For immunocytochemistry assays, GFP-tagged Sur8-expressing cells grown on p-L-O and fibronectincoated cover glasses (Sigma-Aldrich) were fixed with $4 \%$ paraformaldehyde (PFA) for 10 minutes. After washing with PBS, cells were counterstained with 4', 6-diamidino-2-phenylindole (DAPI; Sigma-Aldrich) prior to mounting.

Immunoprecipitation was performed as previously described [25]. For ubiquitination assays, HEK293 cells transfected with plasmids expressing ubiquitin were lysed with lysis buffer $(10 \mathrm{mM}$ Tris- $\mathrm{HCl} \mathrm{pH} 7.5,150 \mathrm{mM} \mathrm{NaCl}$, $1 \mathrm{mM}$ EDTA, $0.1 \% \mathrm{NP}-40,10 \mathrm{mM} \mathrm{NaF}, 1 \mathrm{mM} \mathrm{Na} \mathrm{VO}_{4}$, $1 \mathrm{mM}$ PMSF, and protease inhibitors) and then performed in a process similar to that of the immunoprecipitation assay.

\section{Purification of recombinant proteins and in vitro kinase assay}

Glutathione-S-transferase-(GST)-tagged Sur8-WT was inserted into a pGEX-4T-1 vector using $\mathrm{XhoI}$ and 
BamHI restriction sites and expressed in Escherichia coli. Cell lysates were incubated with glutathione-sepharose4B bead (Sigma-Aldrich) for 1 hour at $4^{\circ} \mathrm{C}$ and GST-Sur8 recombinant proteins were eluted with reduced glutathione (Sigma-Aldrich). In vitro kinase assays were performed by incubation of purified GST-tagged Sur8 with either GSTPKC $\alpha$ (Signal Chem) or GST-PKC $\delta$ (Signal Chem) for 2 hours at $30^{\circ} \mathrm{C}$ in $20 \mu \mathrm{L}$ of reaction buffer containing 50 $\mathrm{mM}$ Tris-HCl (pH 7.5), $10 \mathrm{mM} \mathrm{MgCl}, 1 \mathrm{mM}$ DTT, 10 $\mathrm{mM}$ ATP, and $5 \mu \mathrm{Ci}$ of $\left[\gamma_{-}{ }^{32} \mathrm{P}\right]$ ATP. The reaction mixtures were resolved by SDS-PAGE, and phosphorylated Sur8 was visualized by autoradiography.

\section{Cell proliferation, soft agar, and colony-forming assays}

For proliferation assays, cells were seeded at a density of $5 \times 10^{3}$ cells/well in a 96-well culture plate and treated with or without FGF2 $(20 \mathrm{ng} / \mathrm{mL})$ for 72 hours. Cell growth was investigated by a 3-(4,5-dimethylthiazol2-yl)-2,5-diphenyltetrazolium bromide (MTT)-based semi-automated colorimetric assay according to the manufacturer's instructions.

Anchorage-independent soft agar and the foci formation assays were performed as previously described [13].

\section{Migration and invasion assays}

For migration assays, cells were grown to confluence in a 12-well plate. Following $10 \mu \mathrm{g} / \mathrm{mL}$ mitomycin C treatment (Roche, Indianapolis, IN) for 1 hour to inhibit proliferation, cells were wounded using a $200 \mu \mathrm{L}$ pipette tip and further cultured with or without FGF2 for 48 hours. The percent of wound closure was measured as the relative ratio of residual wound area and the original wound area.

For invasion assays, $3 \times 10^{4}$ cells/ $200 \mu \mathrm{L}$ were seeded on matrigel-coated invasion chambers (BD Bioscience, Bedford, MA) in a 24-well plate with or without FGF2. Cells were allowed to invade for 18 hours. The cells were fixed using 4\% PFA stained with $0.1 \%$ crystal violet. Images were taken under microscope at $40 \times$ magnification.

\section{TMA and immunohistochemistry}

The colorectal cancer TMA (NBP-47195) was purchased from Novus Biologicals. The TMA specimens consisting of 16 pairs of patient-matched adjacent normal and tumor tissues were subjected to immunohistochemistry analysis, following the procedure as previously described [25]. Images of each specimen were taken using a bright field microscope (Nikon ECLIPSE 80i). For the measurement of the cytosolic expression levels of proteins, the TMA slides were quantified using the IHC profiler plugin [39].

\section{Statistical analyses}

Statistical analyses were performed using Microsoft Excel or GraphPad Prism. All data are represented as the mean \pm standard deviation. Statistical differences were determined using Student's $t$-test and considered statistically significant as follows: ${ }^{*} P<0.05,{ }^{* *} P<0.005,{ }^{* * *} P<0.001$.

\section{CONFLICTS OF INTEREST}

Authors have no potential or current conflicts of interest to declare.

\section{GRANT SUPPORT}

This research was supported by grants from the National Research Foundation of Korea (NRF) funded by the Ministry of Science, ICT and Future Planning (MSIP) (2016R1A5A1004694, 2015R1A2A05001873). K.H. Lee was supported by a Brain Korea 21 (BK21) Plus studentship from the NRF.

\section{REFERENCES}

1. Ferrell JE Jr. What do scaffold proteins really do? Sci STKE. 2000; 2000: pe1.

2. Pawson T, Scott JD. Signaling through scaffold, anchoring, and adaptor proteins. Science. 1997; 278: 2075-80.

3. Choi KY, Satterberg B, Lyons DM, Elion EA. Ste5 tethers multiple protein kinases in the MAP kinase cascade required for mating in S. cerevisiae. Cell. 1994; 78: 499-512.

4. Elion EA. Routing MAP kinase cascades. Science. 1998; 281: 1625-6.

5. Levchenko A, Bruck J, Sternberg PW. Scaffold proteins may biphasically affect the levels of mitogen-activated protein kinase signaling and reduce its threshold properties. Proc Natl Acad Sci U S A. 2000; 97: 5818-23.

6. Dhanasekaran DN, Kashef K, Lee CM, Xu H, Reddy EP. Scaffold proteins of MAP-kinase modules. Oncogene. 2007; 26: 3185-202.

7. McCubrey JA, Steelman LS, Chappell WH, Abrams SL, Wong EW, Chang F, Lehmann B, Terrian DM, Milella M, Tafuri A, Stivala F, Libra M, Basecke J, et al. Roles of the Raf/MEK/ERK pathway in cell growth, malignant transformation and drug resistance. Biochim Biophys Acta. 2007; 1773: 1263-84.

8. Fang JY, Richardson BC. The MAPK signalling pathways and colorectal cancer. Lancet Oncol. 2005; 6: 322-7.

9. Rodriguez-Viciana P, Oses-Prieto J, Burlingame A, Fried M, McCormick F. A phosphatase holoenzyme comprised of Shoc2/Sur8 and the catalytic subunit of PP1 functions as an M-Ras effector to modulate Raf activity. Mol Cell. 2006; 22: 217-30. 
10. Young LC, Hartig N, Munoz-Alegre M, Oses-Prieto JA, Durdu S, Bender S, Vijayakumar V, Vietri Rudan M, Gewinner C, Henderson S, Jathoul AP, Ghatrora R, Lythgoe MF, et al. An MRAS, SHOC2, and SCRIB complex coordinates ERK pathway activation with polarity and tumorigenic growth. Mol Cell. 2013; 52: 679-92.

11. Aguzzi MS, Faraone D, D'Arcangelo D, De Marchis F, Toietta G, Ribatti D, Parazzoli A, Colombo P, Capogrossi MC, Facchiano A. The FGF-2-derived peptide FREG inhibits melanoma growth in vitro and in vivo. Mol Ther. 2011; 19: 266-73.

12. Graeven U, Rodeck U, Karpinski S, Jost M, Philippou $\mathrm{S}$, Schmiegel W. Modulation of angiogenesis and tumorigenicity of human melanocytic cells by vascular endothelial growth factor and basic fibroblast growth factor. Cancer Res. 2001; 61: 7282-90.

13. Lee YM, Kaduwal S, Lee KH, Park JC, Jeong WJ, Choi KY. Sur8 mediates tumorigenesis and metastasis in colorectal cancer. Exp Mol Med. 2016; 48: e249.

14. Kent KC, Mii S, Harrington EO, Chang JD, Mallette S, Ware JA. Requirement for protein kinase $\mathrm{C}$ activation in basic fibroblast growth factor-induced human endothelial cell proliferation. Circ Res. 1995; 77: 231-8.

15. Garg R, Benedetti LG, Abera MB, Wang H, Abba M, Kazanietz MG. Protein kinase $\mathrm{C}$ and cancer: what we know and what we do not. Oncogene. 2014; 33: 5225-37.

16. Hernandez-Maqueda JG, Luna-Ulloa LB, Santoyo-Ramos P, Castaneda-Patlan MC, Robles-Flores M. Protein kinase $\mathrm{C}$ delta negatively modulates canonical Wnt pathway and cell proliferation in colon tumor cell lines. PLoS One. 2013; 8: e58540.

17. Pysz MA, Leontieva OV, Bateman NW, Uronis JM, Curry KJ, Threadgill DW, Janssen KP, Robine S, Velcich A, Augenlicht LH, Black AR, Black JD. PKCalpha tumor suppression in the intestine is associated with transcriptional and translational inhibition of cyclin D1. Exp Cell Res. 2009; 315: 1415-28.

18. Scaglione-Sewell B, Abraham C, Bissonnette M, Skarosi SF, Hart J, Davidson NO, Wali RK, Davis BH, Sitrin M, Brasitus TA. Decreased PKC-alpha expression increases cellular proliferation, decreases differentiation, and enhances the transformed phenotype of $\mathrm{CaCo}-2$ cells. Cancer Res. 1998; 58: 1074-81.

19. Mimeault M, Batra SK. New promising drug targets in cancer- and metastasis-initiating cells. Drug Discov Today. 2010; 15: 354-64.

20. Rosa DD, Ismael G, Lago LD, Awada A. Molecular-targeted therapies: lessons from years of clinical development. Cancer Treat Rev. 2008; 34: 61-80.

21. McCubrey JA, Steelman LS, Chappell WH, Abrams SL, Franklin RA, Montalto G, Cervello M, Libra M, Candido S, Malaponte G, Mazzarino MC, Fagone P, Nicoletti F, et al. Ras/Raf/MEK/ERK and PI3K/PTEN/Akt/mTOR cascade inhibitors: how mutations can result in therapy resistance and how to overcome resistance. Oncotarget. 2012; 3: 1068-111. https://doi.org/10.18632/oncotarget.659.

22. Oikonomou E, Koustas E, Goulielmaki M, Pintzas A. BRAF vs RAS oncogenes: are mutations of the same pathway equal? Differential signalling and therapeutic implications. Oncotarget. 2014; 5: 11752-77. https://doi. org/10.18632/oncotarget.2555.

23. Misale S, Yaeger R, Hobor S, Scala E, Janakiraman M, Liska D, Valtorta E, Schiavo R, Buscarino M, Siravegna G, Bencardino K, Cercek A, Chen CT, et al. Emergence of KRAS mutations and acquired resistance to anti-EGFR therapy in colorectal cancer. Nature. 2012; 486: 532-6.

24. Stuart DD, Sellers WR. Targeting RAF-MEK-ERK kinasescaffold interactions in cancer. Nat Med. 2013; 19: 538-40.

25. Kaduwal S, Jeong WJ, Park JC, Lee KH, Lee YM, Jeon SH, Lim YB, Min DS, Choi KY. Sur8/Shoc2 promotes cell motility and metastasis through activation of Ras-PI3K signaling. Oncotarget. 2015; 6: 33091-105. https://doi. org/10.18632/oncotarget.5173.

26. Nguyen A, Burack WR, Stock JL, Kortum R, Chaika OV, Afkarian M, Muller WJ, Murphy KM, Morrison DK, Lewis RE, McNeish J, Shaw AS. Kinase suppressor of Ras (KSR) is a scaffold which facilitates mitogen-activated protein kinase activation in vivo. Mol Cell Biol. 2002; 22: 3035-45.

27. Johnson M, Sharma M, Henderson BR. IQGAP1 regulation and roles in cancer. Cell Signal. 2009; 21: 1471-8.

28. Jameson KL, Mazur PK, Zehnder AM, Zhang J, Zarnegar B, Sage J, Khavari PA. IQGAP1 scaffold-kinase interaction blockade selectively targets RAS-MAP kinase-driven tumors. Nat Med. 2013; 19: 626-30.

29. Dhawan NS, Scopton AP, Dar AC. Small molecule stabilization of the KSR inactive state antagonizes oncogenic Ras signalling. Nature. 2016; 537: 112-6.

30. Kolch W. Coordinating ERK/MAPK signalling through scaffolds and inhibitors. Nat Rev Mol Cell Biol. 2005; 6: 827-37.

31. Turner N, Grose R. Fibroblast growth factor signalling: from development to cancer. Nat Rev Cancer. 2010; 10: 116-29.

32. Antal CE, Hudson AM, Kang E, Zanca C, Wirth C, Stephenson NL, Trotter EW, Gallegos LL, Miller CJ, Furnari FB, Hunter T, Brognard J, Newton AC. Cancerassociated protein kinase $\mathrm{C}$ mutations reveal kinase's role as tumor suppressor. Cell. 2015; 160: 489-502.

33. Oster $\mathrm{H}$, Leitges $\mathrm{M}$. Protein kinase $\mathrm{C}$ alpha but not PKCzeta suppresses intestinal tumor formation in ApcMin/+ mice. Cancer Res. 2006; 66: 6955-63.

34. Lu Z, Liu D, Hornia A, Devonish W, Pagano M, Foster DA. Activation of protein kinase $\mathrm{C}$ triggers its ubiquitination and degradation. Mol Cell Biol. 1998; 18: 839-45.

35. Cressman CM, Mohan PS, Nixon RA, Shea TB. Proteolysis of protein kinase $\mathrm{C}: \mathrm{mM}$ and microM calcium-requiring calpains have different abilities to generate, and degrade the free catalytic subunit, protein kinase M. FEBS Lett. 1995; 367: $223-7$. 
36. Saido TC, Mizuno K, Suzuki K. Proteolysis of protein kinase $\mathrm{C}$ by calpain: effect of acidic phospholipids. Biomed Biochim Acta. 1991; 50: 485-9.

37. Savart M, Letard P, Bultel S, Ducastaing A. Induction of protein kinase $\mathrm{C}$ down-regulation by the phorbol ester TPA in a calpain/protein kinase C complex. Int J Cancer. 1992; 52: 399-403.

38. Koo KH, Jeong WJ, Cho YH, Park JC, Min DS, Choi KY. $\mathrm{K}-\mathrm{R}$ as stabilization by estrogen via PKCdelta is involved in endometrial tumorigenesis. Oncotarget. 2015; 6: 21328-40. https://doi.org/10.18632/oncotarget.4049.

39. Varghese F, Bukhari AB, Malhotra R, De A. IHC Profiler: an open source plugin for the quantitative evaluation and automated scoring of immunohistochemistry images of human tissue samples. PLoS One. 2014; 9: e96801. 